\title{
Deterioration Prediction Model of Multi-Layer Coating Material and its Reference Service Life Evaluation in Terms of Carbonation Control Effect
}

\author{
Kotaro Etchuya ${ }^{1}$, Keiichi Imamoto ${ }^{2}$ and Chizuru Kiyohara ${ }^{2}$ \\ ${ }^{1}$ Japan Building Coating Materials Association, ecchuya@nsk-web.org \\ ${ }^{2}$ Tokyo University of Science, Dr.Eng, imamoto@rs.tus.ac.jp
}

\begin{abstract}
In this paper, authors propose a method to predict deterioration of exterior finishes using Markov Chain Model based on field survey results on cracks of exterior finishes of existing RC buildings. There existed correlation between degradation of finishing and carbonation progress. Authors propose the service life prediction approach to focus on the carbonation suppression effect into the concrete considering progress of exterior finish deterioration.
\end{abstract}

Keywords: Masonry Coating, Visual Survey, Markov Chain Model, Service Life Prediction Method.

\section{Introduction}

Carbonation of concrete is one of the factors that determines the life of reinforced concrete buildings. In general, it is possible to prevent the carbonation and extend the life by applying an exterior coating material to the outer wall.

It is difficult to predict the degradation of finishing coatings because type of material, parts used, construction level and maintenance level interactively affect the degradation of coating material.

On the other hand, since the exterior finishing coatings is required to have protection performance against reinforced concrete, its end would be evaluated as a time when the carbonation suppression effect decreases a certain value. However, there are many unknown points about the relationship between the deterioration of the exterior coating material and the reduction of the carbonation suppression effect.

In this study, authors investigate the deterioration state of actual buildings throughout field survey, and propose a deterioration prediction method of exterior coating materials by using the Markov chain model, which is one of the comprehensive probabilistic models based on the results of the survey. In addition, focusing on change of carbonation suppression effect with deterioration of the exterior coating material, authors propose a method for evaluating the service life of the coating material.

\section{Development of Deterioration Prediction Method for Exterior Coating Material}

\subsection{Collection of Deterioration Data of Exterior Coating Materials in Real BSuildings}

Four reinforced concrete buildings shown in Table1 were surveyed from 2012 to 2016. It should be noted that "Age from Repaint" means the age of the exterior coating material from renovation year to 2016. In addition, since the four buildings locate in the neighborhood, it would be a 
close environmental condition. The number of renovations of the exterior coating material is one, but years of the renovation is different.

Table 1. Surveyed Buildings.

\begin{tabular}{|c|c|c|c|c|}
\hline \multirow{2}{*}{} & \multicolumn{4}{|c|}{ Survey Buildings } \\
\cline { 2 - 5 } & A & B & C & D \\
\hline Construction & \multicolumn{4}{|c|}{ reinforced concrete construction } \\
\hline Stories & 4 & 4 & 4 & 12 \\
\hline Design Strength & $18 \mathrm{~N} / \mathrm{mm}^{2}$ & $18 \mathrm{~N} / \mathrm{mm}^{2}$ & $21 \mathrm{~N} / \mathrm{mm}^{2}$ & $21 \mathrm{~N} / \mathrm{mm}^{2}$ \\
\hline Year of construction & 1978 & 1977 & 1977 & 1977 \\
\hline Year of Repaint & 2010 & 2008 & 2001 & 1997 \\
\hline Age from Repaint & 6 old & 8 old & 15 old & 19 old \\
\hline $\begin{array}{c}\text { Coating Material } \\
\text { (construction) }\end{array}$ & \multicolumn{5}{|c|}{ Multi-layer Coating Material (E Type) } \\
\hline $\begin{array}{c}\text { Coating Material } \\
\text { (repaint) }\end{array}$ & \multicolumn{5}{|c|}{ Synthetic Resin Emulsion Paint } \\
\hline Color of finish & \multicolumn{5}{|c|}{ white } \\
\hline
\end{tabular}

Survey items are as follows.

Table 2. Classification of Crack Degradation.

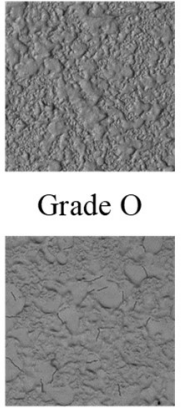

Grade II

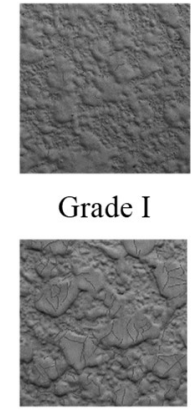

Grade III

\begin{tabular}{l} 
(range $50 \mathrm{~mm} \times 50 \mathrm{~mm})$ \\
Grade O : \\
No crack \\
Grade I : \\
A few cracks \\
Grade II : \\
About 10 cracks \\
Grade III : \\
Mesh type cracks overall \\
\hline
\end{tabular}
Grade O : No crack Grade I : (1)

(1) Cracks: Visual cracks in the outer wall were classified into four grades. About 100 to 200 points with each point of $50 \mathrm{~mm} \times 50 \mathrm{~mm}$ area for each building were surveyed. Grade detection was performed using a standard sample shown in Table 2.

(2) Carbonation: Carbonation depth was measured by phenolphthalein solution method with core specimens.

Fig. 1 shows relationship between elapsed and average crack grade cracking progressed with the passage of time s Fig. 2 shows relationship between elapsed yea can be seen that the progress of carbonation i renovation increases. Since age of each surveyed building is

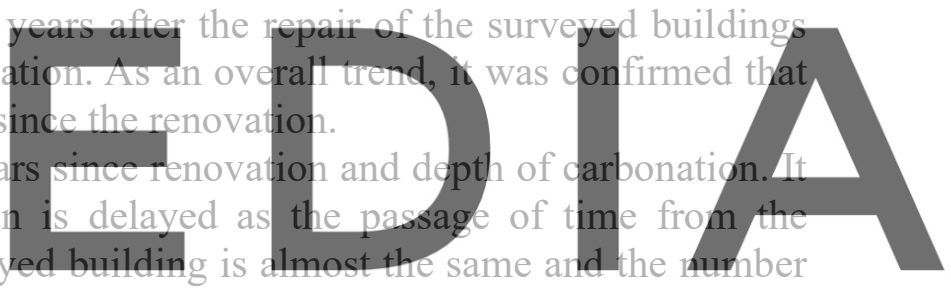
of repaints is one, it would be thought that not only the aging from the renovation to the time

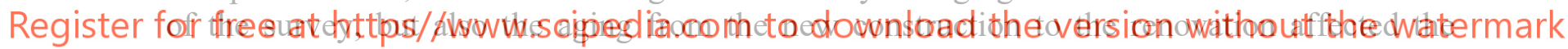
progress of carbonation. Furthermore, the carbonation progressed in the buildings where the renovation time was significantly delayed.

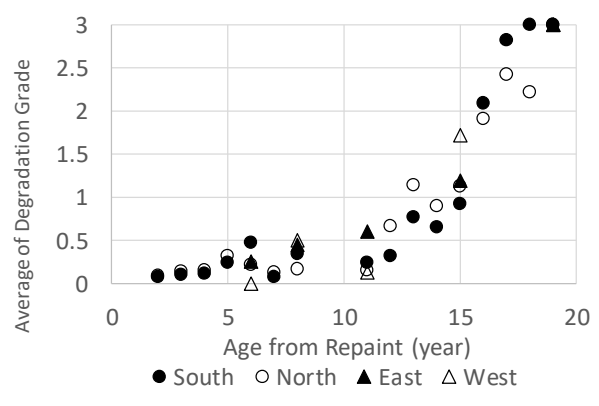

Figure 1. Crack Degradation.

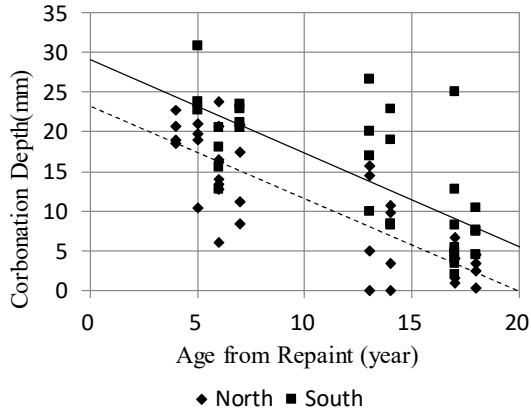

Figure 2. Carbonation.

\subsection{Deterioration Prediction of Exterior Coating Materials}

The Markov chain model is a probabilistic model for future condition prediction, and it is a 
macro model that is used when it is difficult to predict by the accumulation of each affecting factor. Here, in the degradation grades from $\mathrm{O}$ to III as shown in Fig.3, the transition probability $\mathrm{Xn}$ is assumed to transit from certain degradation grade to the next grade after a certain time $\mathrm{t}$. It is assumed that the distribution of the deterioration grade at any time can be simulated. This model has irreversible features, and its equation is represented in Fig.4.

As shown in Fig. 1, cracking phenomenon, which is the degradation phenomenon of exterior coating, tends to progress with time, and is consistent with the irreversible characteristics of the Markov chain model used in this study.

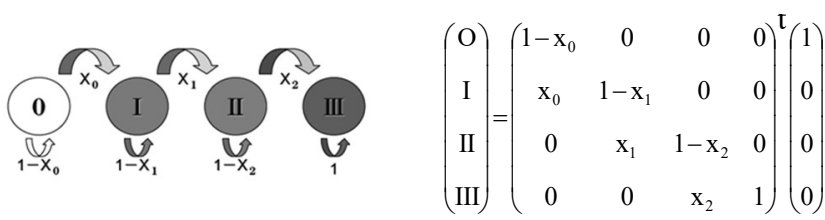

Figure 3. Conceptual Figure 4. Determinant

Diagram of Markov Chain :epresentation of Markov Chain Model. Model.

Average values of the transition probability based on the results of the crack survey from 2012 to 2016 are shown in Table3. In addition, the results of prediction of deterioration of cracks by Markov chain model using the transition probability are shown in Fig.5.

Feature of this mode building, but the propor 0 decreases accordingl progress, and crack gi most significant degradation, increases.

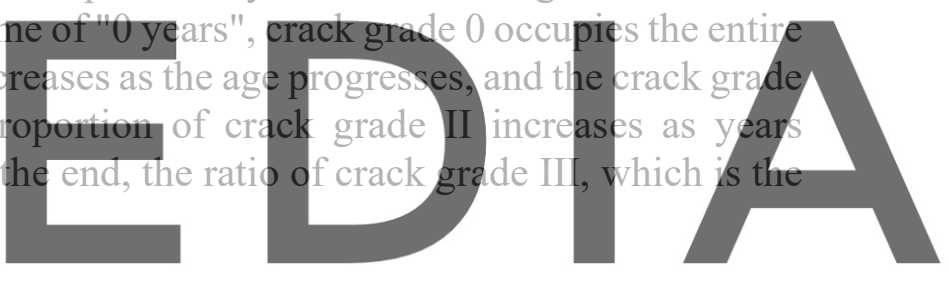

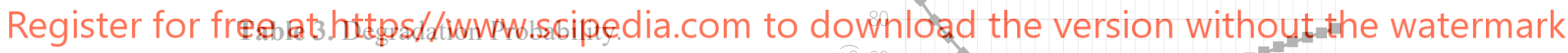

\begin{tabular}{|c|c|c|c|}
\hline & $x 0$ & $x 1$ & $x 2$ \\
\hline Max & 0.384 & 0.396 & 0.400 \\
\hline Min & 0.016 & 0.015 & 0.004 \\
\hline Average & 0.108 & 0.116 & 0.178 \\
\hline
\end{tabular}

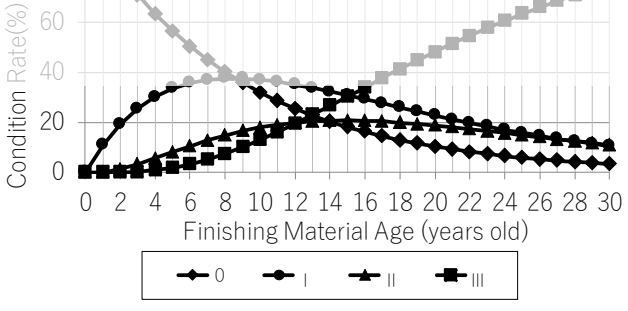

Figure 5. Prediction of Cracking.

\section{Relationship between Cracking and Carbonation Suppression Effect}

\subsection{Decrease in Carbonation Suppression Effect by Cracking}

Authors examine relationship between cracking and carbonation suppression effect.

Akio, T. (2013) showed that there is a certain correlation between surface air permeability coefficient and carbonation rate coefficient of existing RC buildings. In this study, time change of carbonation suppression effect of a multi-layer coating coating material was evaluated by the 
air permeability test. Crack of the coating material is degradation phenomenon as shown in table 2 and $\mathrm{CO}_{2}$ induced carbonation would occur at the cracks which strongly affects air permeability of the coating. Hence, the deterioration of the coating material and its relation to carbonation would be evaluated with surface air permeability.

\subsection{Verification at Laboratory}

Multi-layer coating materials for exterior finishing used in reinforced concrete buildings often composed of three layers that are a top coating layer that protects the outer wall from solar radiation and rain, a main material layer that provides texture and a primer layer that improves adhesion to the frame. Here, in order to confirm the possibility that the protective effect of the coating material would be reduced by cracking of the top coating material, the change of air permeability of the surface layer was measured at laboratory.

An outline of test specimen is shown in Fig.6. First, sewing thread is laid down at different intervals on calcium plate. Next, an acrylic resin emulsion paint as an overcoat layer for the exterior coating material was applied to the calcium plate with a roller. After 60 minutes, the sewing thread was pulled out to reproduce pseudo crack.

Surface permeability was evaluated using a double chamber method (1992) before the sewing machine was laid down.

\section{Fig. 7 shows the ratios of the air permeability coefficient of the test specimen before and after} crack initiation.

\section{Here, "crack length"}

of the measuring apparat

It can be seen that the

the pseudo crack, and fi

carbonate plate beford coating

This might indicate that when the cracks in
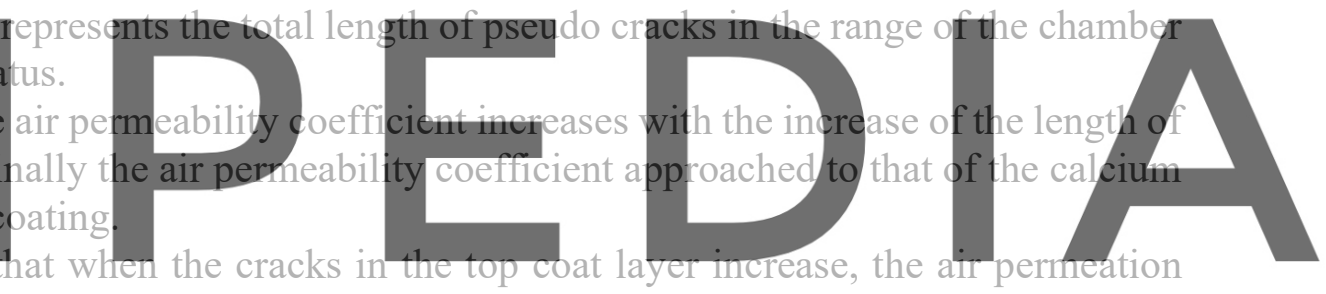

becomes easier and the carbonation suppressing effect decreases. And the close air permeability

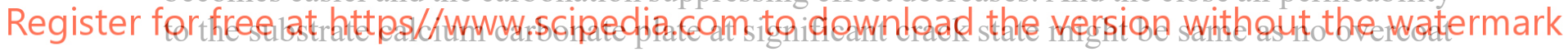
layer applied.

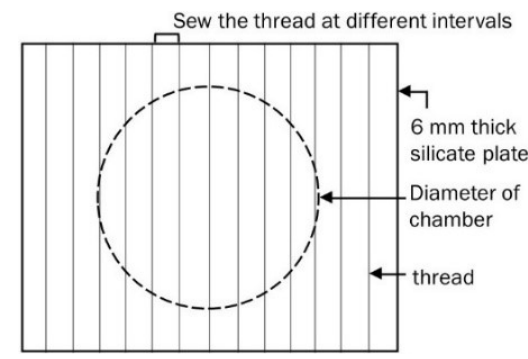

Figure 6. Test Models.

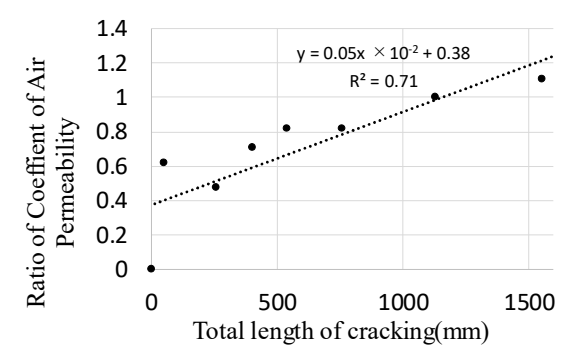

Figure 7. Relation of cracking and Coefficient of Air Permeability.

\subsection{Survey of Actual Buildings}

Crack and air permeability of actual buildings were surveyed. Nine reinforced concrete buildings estates shown in Table 4 were surveyed at a position of about $1.5 \mathrm{~m}$ height above the ground and a visual inspection of the cracks and surface air permeability tests were conducted 
at the same location. As a feature of these buildings, each building is under almost same environmental conditions and age of construction and types of coating materials are same.

Fig. 8 shows secular change of crack grade and surface air permeability. As the years progress, the crack grade and air permeability coefficient tend to increase. As a result, there was a possibility that there was a temporary correlation between the cracks and air permeability of the coating material.

Table 4. Survey Buildings.

\begin{tabular}{|c|c|c|}
\hline Buildings & Building Age & Finishing Material \\
\hline $\mathrm{A}$ & $11, \quad 14, \quad 18$ & Sprayed Tile \\
\hline B & $13,16,18$ & $\begin{array}{c}\text { Multi-layer Finish Material } \\
\text { (Thick E Type Treated Protrusion) }\end{array}$ \\
\hline $\mathrm{C}$ & $7,9,11$ & Sprayed Tile Thick E Type \\
\hline
\end{tabular}

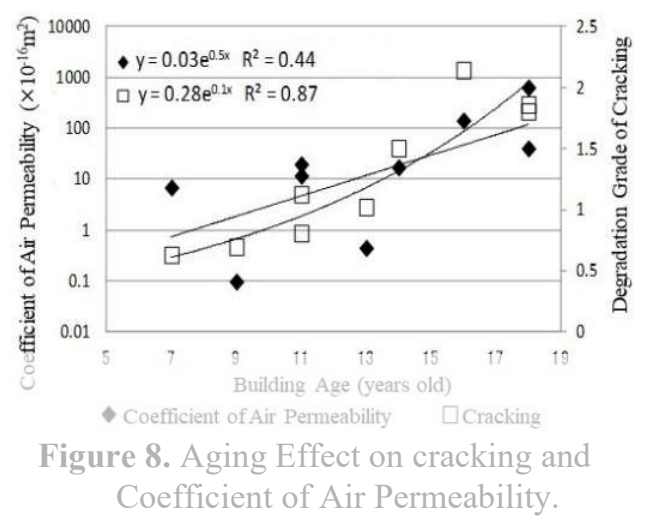

3.4 Verification Using a Markov Chain Model for Deterioration Prediction Simulation

Kei.M (2013) evaluated period when carbonation rate coefficient of finished concrete became equal to that of exposed concrete due to deterioration of the coating film as the service life of

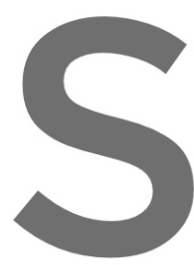
the coating material. It w of the coating materia according to time from assumed to be critical. relationship between years that exceeded the
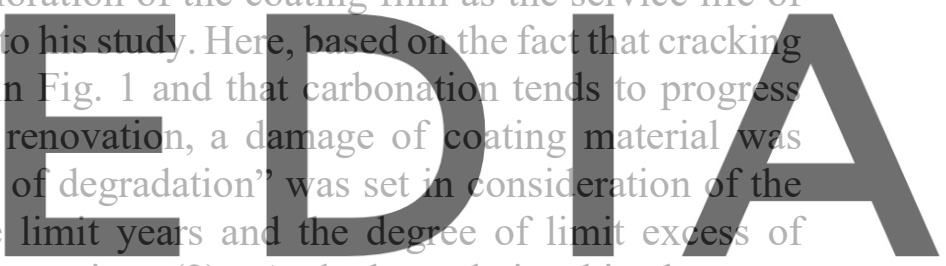

deterioration as shown in the following equation (2). And the relationship between

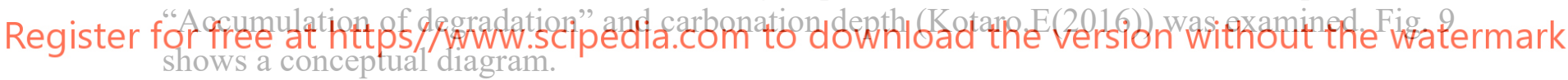

$$
D_{a}=\sum_{n=1}^{N} \sum_{t=1}^{T(n)-L}\left(d_{n}(L+t)-d_{n}(L)\right)
$$

Here,

Da: Accumulation of degradation", N(times): Number of paintings including when building exterior coating materials, $\mathrm{T}(\mathrm{n})($ year): Number of years from the time of painting to the time of renovation (when $\mathrm{n}=\mathrm{N}$, from the time of painting to the time of survey), $\mathrm{L}$ (year): Marginal years for exterior coating materials, $\mathrm{dn}(\mathrm{x})$ : Represents the ratio of degradation grade III $(0<\mathrm{dn}$ $(\mathrm{x})<1$ ) of Markov simulation at the time of $\mathrm{n}$ times of coating $\mathrm{n}$ times, and is considered only when the age exceeds the limit years $(x>L)$.

Based on previous research (2011), the relationship between "Accumulation of degradation" and the mean of the carbonation depth of each building assuming the limit of 13 years is shown in Fig. 10 for the surveyed building shown in Table1. It can be seen that the average of the carbonation depth of the building increases as "Accumulation of degradation" increases, and there is a possibility that there is a certain relationship between the crack and the carbonation suppression effect. 
Table 5 shows list of the all surveyed buildings. Although these buildings are different specification and subjected to different environmental conditions, design standard strength was close to each other. Hence, "(1) Crack" and "(2) Carbonation depth" using the methods described in chapter 2 were investigated. Fig. 11 shows relationship between "Accumulation of degradation" and carbonation depth for each survey target. Although the correlation of Fig.11 was lower than that of Fig. 10, a certain degree of correlation was kept. Thus, there would be correlation between the cracking and carbonation inhibitory effect of the multi-layer coating material.

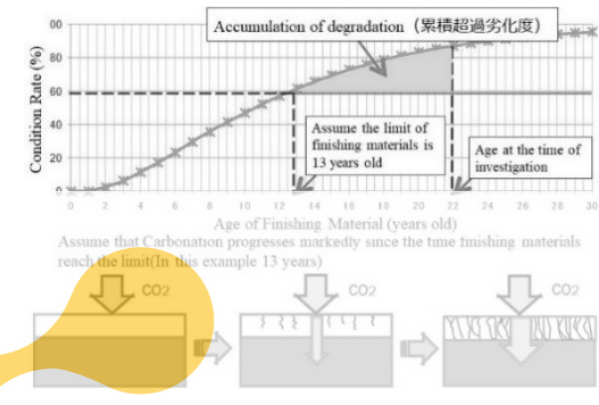

Figure 9. Models of Accumulation of degradation.

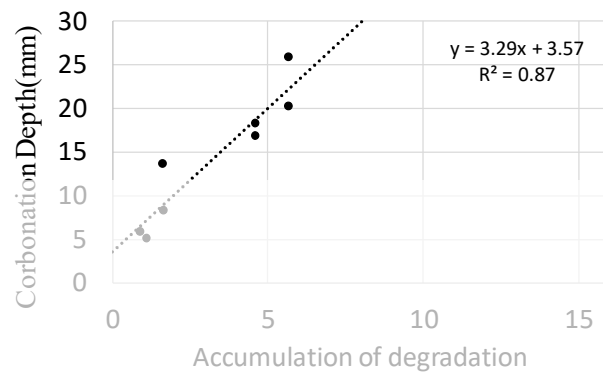

Figure 10. Relation of Accumulation of degradation and Carbonation depth.
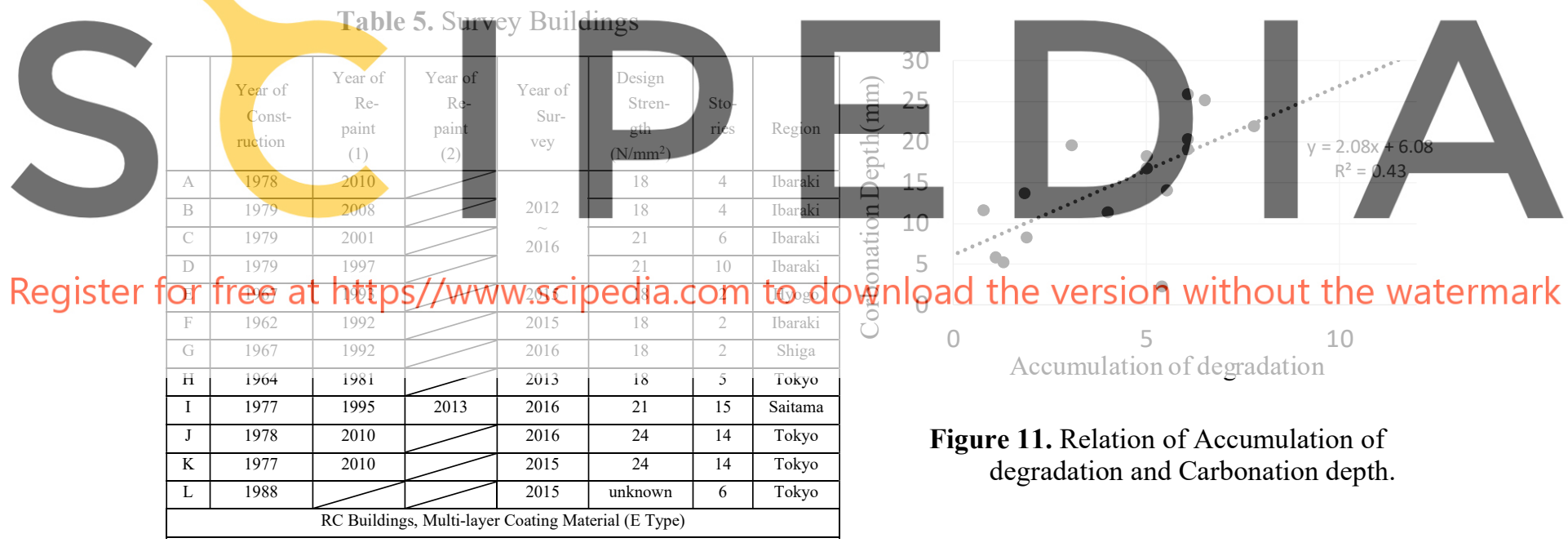

$00 \%$

the version without the watermark

Accumulation of degradation

Figure 11. Relation of Accumulation of degradation and Carbonation depth.

\section{A proposal for Service Life}

In Fig. 10, it would be clear that carbonation depth would be 0, if "Accumulation of degradation" is 0 . That means that the regression line should pass through the origin. At this that the regression line passed a bit other point of the figure because the limit age of the coating materials was assumed to be 13 years. Therefore, authors set the new limit years so that the regression line approaches the origin. In the subject of this survey, the regression straight line passed the origin when the limit age was 10 years. Fig. 12 shows the relationship between "Accumulation of degradation" and the carbonation depth with the critical age of 10 years.

When the limit service life is assumed to be 10 years, the deterioration rate shown in Fig. 5 (the 
ratio of deterioration grade III) would be $16.0 \%$ with transition probabilities shown in Table 3 . It would be possible to consider the time when this deterioration rate is reached based on carbonation of concrete.

As described above, the exterior coating materials can be used to minimize or control the carbonation of concrete by repainting within a range that does not cause "Accumulation of degradation" within 10 years. In this sense, it can be situated as a way of service life consideration.

The relationship between age and "Accumulation of degradation" is shown in Fig. 13 by Equation (2) for the survey target in Table 1.

In addition, the relationship between age and carbonation depth is shown in Fig. 14 by using the approximate expression of the relationship between "Accumulation of degradation" when the limit years as 10 years. On the other hands, if the cover thickness of reinforced concrete is $30 \mathrm{~mm}$, this building will face to the end of life in 36 years unless it is repainted. Here, assuming that the required service life of the building is 100 years and the repainting interval at which carbonation does not reach $30 \mathrm{~mm}$ within 100 years, life cycle assessment of finishing coating in terms of carbonation would be possible. Table 6 shows the prediction of the carbonation depth of buildings when the exterior coating materials are refurbished and the age reaches 100 years. It would be calculated that if the exterior coating material used in this building is repainted every 22 years (Fig.15), carbonation does not reach the reinforcing bars within 100 years.
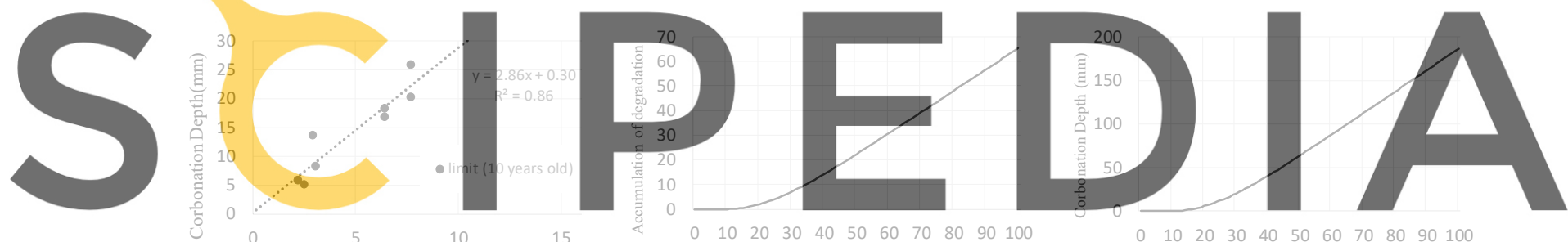

$0 \quad 1020 \quad 3040 \quad 5060 \quad 70 \quad 8090100$

Register for free at https//WwW.scipedia.com to download the version without the watermark Figure 12. Relation of Figure 13. Prediction of Accumulation of degradation and Accumulation of degradation. Carbonation depth.

Table 6. Relation of Repaint interval and Prediction of Carbonation Depth in 100 years.

\begin{tabular}{|c|c||c|c|}
\hline $\begin{array}{c}\text { Repaint interval } \\
\text { (year) }\end{array}$ & $\begin{array}{c}\text { Prediction of } \\
\text { Carbonation } \\
(\mathrm{mm})\end{array}$ & $\begin{array}{c}\text { Repaint interval } \\
\text { (year) }\end{array}$ & $\begin{array}{c}\text { Prediction of } \\
\text { Carbonation } \\
(\mathrm{mm})\end{array}$ \\
\hline 30 & 55.21 & 25 & 41.80 \\
\hline 29 & 50.60 & 24 & 36.33 \\
\hline 28 & 47.11 & 23 & 31.19 \\
\hline 27 & 44.75 & 22 & 26.69 \\
\hline 26 & 43.49 & 21 & 24.05 \\
\hline
\end{tabular}

\section{Summary}

The findings obtained in this study are shown below.

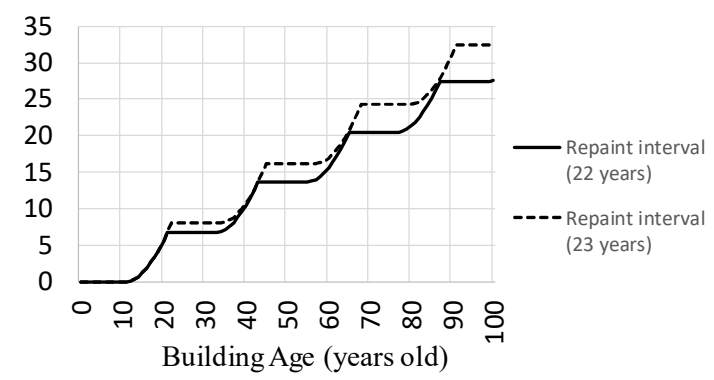

Figure 15. Prediction of Carbonation depth. (repaint interval 22years and 23years) 
- Authors investigated four buildings that were close environmental condition, focusing on cracking of multi-layer coating. As an overall trend, Cracking was confirmed that cracking progressed with the passage of time since the renovation.

- Based on the survey results on cracks in multi-layer coating materials applied to reinforced concrete buildings, authors presented a method for predicting crack degradation using a Markov chain model.

- Authors showed a possibility that there was a correlation between the cracks and air permeability of the coating materials by laboratory experiments and surveys of real buildings. In addition, by considering along with the report that there was a correlation between surface air permeability and carbonation rate coefficient of existing RC buildings, authors showed a possibility that there was a correlation between the cracking and carbonation inhibitory effect of the multi-layer coating materials.

- Authors proposed "Accumulation of degradation" considering the time and grade when the crack exceeded a certain value. And Authors confirmed that there is a certain correlation between the "Accumulation of degradation" and the carbonation depth of the buildings.

- By using the relationship between "Accumulation of degradation" and the carbonation depth of the buildings, Authors suggested the service life for the coating materials to use the buildings for the longest years and the required years.

ORCID

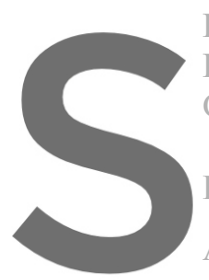

Kotaro Etchuya: https://orcid.org/0000-0002-7858-9420

Kei-ichi Imamoto: https:

Chizuru Kiyohara: https:

References

Akio Tanaka and Kei-ichi Imamoto (2013). Evaluation
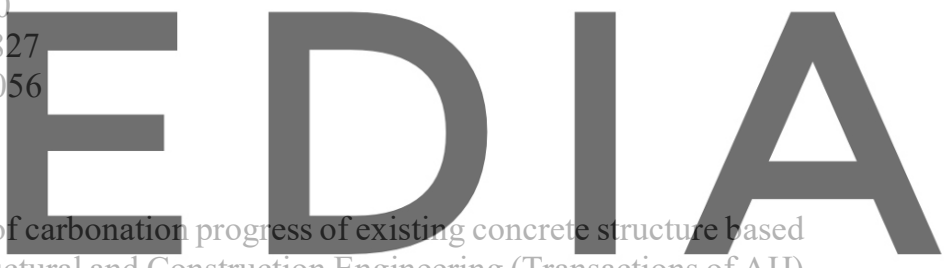

on air permeability of cover concrete, Journal of Structural and Construction Engineering (Transactions of AIJ), No. 691, pp.1539-1545

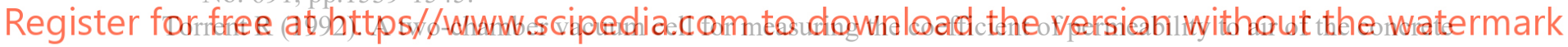
cover on site, Mater. \& Struct., Vol.25, No.150, pp.358-365.

Masanori Kono, Yoshihiro Masuda, Ryota Ochiai and Tomoyuki Karasawa (2004). Study on the carbonation suppressive effects of concrete considering the aging of coating materials for textured finishes, Journal of Structural and Construction Engineering (Transactions of AIJ), Vol.69, No.584, pp.15-21.

Masanori Kono and Yoshihiro Masuda (2006). Verification of the carbonation suppressive effects evaluation method of concrete considering the aging of coating materials or textured finishes using the exposure data, Journal of Structural and Construction Engineering (Transactions of AIJ), Vol.71, No.609, pp.9-14.

Tomoyuki Karasawa and Yoshihiro Masuda (2011). Carbonation suppressive effects of coating materials for textured finishes based on the research of air permeability coefficient and carbonation depth of coating materials for textured finishes of the existing structure, Journal of Structural and Construction Engineering (Transactions of AIJ), Vol.76, No.661, pp.449-454.

Kei Matsuda, Kei-ichi Imamoto, Hiroshi Jinnai and Akiyuki Shimizu (2011). The evaluation of degradation of exterior finishes and its relation to concrete carbonation progress with combination of Markov Chain Model and in-situ non-destructive air permeability test for concrete cover, Journal of Structural and Construction Engineering (Transactions of AIJ), Vol.78, No.683, pp.27-33.

Kotaro Etchuya, Kei-ichi Imamoto, Kenji Motohashi and Chizuru Kiyohara (2016). Estimation of deterioration of exterior finishes and evaluation of carbonation progress of concrete by Markov chain model, Proceedings of the Japan Concrete Institute, pp.729-734. 